\title{
LOCUS CERULEUS LESION BY LOCAL 6-HYDROXYDOPAMINE INFUSION CAUSES MARKD AND SPECIFIC DESTRUCTION OF NORADRENERGIC NEURONS, LONG-TERM DEPLETION OF NOREPINEPHRINE AND THE ENZYMES THAT SYNTHESIZE IT, AND ENHANCED DOPAMINERGIC MECHANISMS IN THE IPSILATERAL CEREBRAL CORTEX ${ }^{1}$
}

\author{
SAMI I. HARIK
}

Departments of Neurology and Pharmacology, Case Western Reserve University School of Medicine, Cleveland, Ohio 44106

Received May 23, 1983; Revised August 26, 1983; Accepted August 30, 1983

\begin{abstract}
The local stereotaxic microinfusion of $5 \mu \mathrm{g}$ of 6-hydroxydopamine in the region of the nucleus locus ceruleus causes severe loss of noradrenergic neurons with little evidence of nonspecific tissue reaction or destruction that could be detected by conventional light microscopic methods. Such lesion is accompanied by a marked and long-term depletion of norepinephrine and comparable loss of activity of its synthesizing enzymes, dopamine $\beta$-hydroxylase and tyrosine hydroxylase, in the ipsilateral cerebral cortex. Locus ceruleus lesion was also found to increase tissue levels of dopamine and its metabolites, 3,4-dihydroxyphenylacetic acid and homovanillic acid, in the ipsilateral cortex. These results add further evidence to support the hypothesis that enhanced dopaminergic mechanisms may play a central role in compensating for chronic cortical noradrenergic denervation.
\end{abstract}

Unilateral lesion of the nucleus locus ceruleus (LC), induced by the local microinfusion of 6-hydroxydopamine (6-OHDA), results in ipsilateral depletion of cortical norepinephine $(\mathrm{NE})$ and provides means of assessing the physiological role(s) of this neuromodulator by defining the changes produced by its depletion. In our laboratory, we have already demonstrated that unilateral LCC lesion is associated with: $(i)$ an increase in the density of $\beta$-adrenoceptors in the ipsilateral cerebral cortex (Sharma et al., 1981), (ii) a similar increase in isoproterenol-induced activity of adenylate cyclase in slices of the ipsilateral cerebral cortex (Harik et al., 1981), and (iii) abnormalities of cerebral oxidative metabolism demonstrted by the prolonged oxidation of cytochrome $a, a_{3}$ after direct electrical cortical stimulation (Harik et al., 1979; LaManna et al., 1981). All of these abnormalities are transient, reaching their maximum about 2 weeks after the lesion, but returning to normal within 4 to 8

\footnotetext{
${ }^{1}$ I thank Drs. P. Gambetti and J. C. de la Torre for their help in the histological studies, P. McMahon and M. Ruch for their technical assistance, and Mrs. Gail Troost for preparing the manuscript. This work was supported by United States Public Health Service Grants NS 18150 and NS 05820 and by grants from the Cleveland Foundation and the American Parkinson's Disease Association.
}

weeks despite the marked persistent loss of cortical NE (Harik et al., 1981).

The transient nature of these abnormalities despite continued depletion of NE suggests that the cerebral cortex is capable of compensatory mechanisms that restore normal function despite loss of endogenous cerebral NE. Such compensatory capabilities are consistent with previous observations of transient behavioral abnormalities after LC lesions (Amaral and Sinnamon, 1977). There are several possible explanations for the apparent recovery of functions after unilateral LC lesion produced by the local microinfusion of 6-OHDA. These possibilities include regeneration of noradrenergic neurons of the LC after their reversible injury by 6-OHDA, compensation by a minority of unaffected neurons for the subtotal loss of LC neurons by 6-OHDA, and/or sprouting of other central or peripheral catecholaminergic systems to replace the degenerated terminals of injured LC neurons.

In this communication, we have attempted to examine these possibilities and to assess the severity and the relative specificity of unilateral LC lesion by 6-OHDA on noradrenergic, dopaminergic, and serotonergic terminals in the ipsilateral cerebral cortex at 2 and 8 weeks after LC lesion. In particular, we asked whether there is evidence to suggest regeneration of LC neurons or sprouting of noradrenergic or dopaminergic systems to 
compensate for the loss of noradrenergic LC neurons. To answer these questions, we evaluated the anatomical extent of the lesion by conventional light microscopy and by histofluorescent microscopy. We also assessed the activity of tyrosine hydroxylase $(\mathrm{TH})$, the rate-limiting biosynthetic step for catecholamines (Levitt et al., $1965)$, and the activity of dopamine $\beta$-hydroxylase (DBH), another important enzyme in the biosynthesis of $\mathrm{NE}$ and a marker for noradrenergic neurons, in the ipsilateral and contralateral cerebral cortex, at 2 and 8 weeks after unilateral LC lesion and in control rats. In addition, we assayed the cerebral cortical concentrations of dopamine (DA) and its metabolites, 3,4-dihydroxyphenylacetic acid (DOPAC) and homovanillic acid (HVA), and another monoamine putative neurotransmitter, 5 -hydroxytryptamine ( 5 - $\mathrm{HT}$, serotonin), and its metabolite, 5-hydroxyindole acetic acid (5-HIAA). We reasoned that compensatory hyperactivity of the remaining noradrenergic neurons after a subtotal LC lesion or regeneration of injured noradrenergic LC neurons may result in recovery of the activities of $\mathrm{TH}$ and $\mathrm{DBH}$ in the ipsilateral cerebral cortex 8 weeks after lesion. On the other hand, recovery of TH activity and increased tissue levels of DA and/or its metabolites in the face of low DBH activity may indicate that dopaminergic systems are compensating for the loss of noradrenergic elements. Evidence for such a possibility has recently been proposed by Logan and Harik (1982) based on the emergence of a high affinity uptake system for DA by homogenates of the cerebral cortex ipsilateral to LC lesion.

We find that 6-OHDA microinfusion into the LC results in almost complete destruction of LC neurons as seen by histofluorescent microscopy with the lesion barely detectable by conventional light microscopy, thus indicating the high specificity of the lesion. We also find that the activities of $\mathrm{TH}$ and $\mathrm{DBH}$ are irreversibly decreased in the ipsilateral cerebral cortex to an extent commensurate with the decrease in NE levels. More importantly, we find that DA, DOPAC, and HVA levels increase significantly in the ipsilateral cerebral cortex. These observations emphasize the relative specificity of the 6-OHDA lesion to the LC and do not support the possibility that such lesion is reversible. The results also provide further evidence to support the hypothesis that sprouting of dopaminergic elements may occur in the cerebral cortex deprived of its noradrenergic innervation. It is possible that such enhanced dopaminergic input may play an important role in mediating compensatory processes.

\section{Materials and Methods}

Animals. Male Wistar rats weighing 175 to $225 \mathrm{gm}$ at the time of the LC lesion were used in all experiments. Rats were kept under diurnal light conditions with free access to laboratory chow and water and were allowed a minimum of 5 days of acclimation before LC lesions were undertaken. The LC was lesioned unilaterally by the local stereotaxic microinjection of $5 \mu \mathrm{g}$ of 6-OHDA base dissolved in $2.5 \mu \mathrm{l}$ of $0.9 \%$ sodium chloride solution containing ascorbic acid, $1 \mathrm{mg} / \mathrm{ml}$, and adjusted to a $\mathrm{pH}$ of 5.5. LC lesion was made under chloral hydrate anes- thesia $(400 \mathrm{mg} / \mathrm{kg}$, i.p.) and after rats were pretreated with pargyline $(50 \mathrm{mg} / \mathrm{kg}$, i.p.) The freshly prepared 6 OHDA solution was slowly infused through a glass micropipette with a tip diameter of about $50 \mu \mathrm{m}$ over a period of $5 \mathrm{~min}$. The details of the lesion procedure have been reported previously (Harik et al., 1981; LaManna et al., 1981). LC lesions were made unilaterally with equal distribution between the right and left sides. A control group of rats was anesthetized and treated with pargyline, but no intracranial injections were given. We have previously demonstrated that rats receiving vehicle infusions into the LC after chloral hydrate anesthesia and pargyline pretreatment did not differ from those without LC injections (LaManna et al., 1981).

After recovering from anesthesia, the rats were returned to their cages, where they were kept for 2 or 8 weeks before further experiments were made. The operative mortality did not exceed $5 \%$. Rats with unilateral LC lesion did not show any gross behavioral abnormality when compared to the control group of rats.

Biochemical studies were performed 2 or 8 weeks after LC lesion or sham operations. The rats were decapitated and the brain quickly removed and cortical samples were taken from symmetrical areas of the temporoparietal regions bilaterally. The cortical samples were frozen immediately in liquid nitrogen and stored at $-100^{\circ} \mathrm{C}$ until asayed for $\mathrm{TH}$ activity, $\mathrm{DBH}$ activity, and tissue concentrations of NE, DA, DOPAC, HVA, 5-HT, and 5HIAA. Three groups of rats were used. The first $(22$ lesioned rats and 14 controls) was used to assay DBH activity and NF, levels. The second (18 lesioned and 10 control rats) was used for the assay of TH activity and NE levels, and in some rats in this group tissue levels of monoamines and their metabolites were determined. A third group of rats was used for assay of monamines and their metabolites.

Structural morphological studies were performed in 5 rats with unilateral LC lesion. The extent of tissue damage produced by 6-OHDA microinfusion was assessed in three rats in $6 \mu \mathrm{m}$ thick cross-sections of the pons stained with hematoxylin and eosin and with cresyl violet. In the other two rats, monoamine histofluorescence was studied in cryostat sections of the cerebral cortex and the pons by the method of de la Torre (1980). The latter rats were pretreated with nialimide, a potent monoamine oxidase inhibitor, $1 \mathrm{hr}$ prior to sacrifice to enhance monoamine fluorescence.

In all rats the success of LC lesion was ascertained by the magnitude of NE depletion in the ipsilateral cerebral cortex. LC lesion was considered successful when ipsilateral cortical NE was reduced by more than $70 \%$ of the contralateral side. Only successfully lesioned rats were included in data analysis.

$D B H$ assay. DBH was assayed by the radioenzymatic procedure of Molinoff et al. (1971) with few modifications. Cerebral cortical tissue was homogenized in $40 \mathrm{vol}$ of $0.05 \mathrm{M}$ Tris buffer, $\mathrm{pH} 6.0$, containing $0.1 \%$ Triton $\mathrm{X}$ 100. Homogenates were centrifuged at $15,000 \times g$ for 30 min at 0 to $4^{\circ} \mathrm{C}$, and the supernatant was used for the assay procedure. Two hundred microliters of the supernatant were added to the reaction mixture containing 25 $\mu \mathrm{l}$ of $0.5 \mathrm{~m}$ sodium fumarate, $\mathrm{pH} 6.0 ; 20 \mu \mathrm{l}$ of $6 \mathrm{~mm}$ 
pargyline; $25 \mu \mathrm{l}$ of $0.05 \mathrm{M}$ ascorbic acid, $\mathrm{pH} 6.0 ; 10 \mu \mathrm{l}$ of $1 \mathrm{~m}$ Tris buffer, $\mathrm{pH} 6.0 ; 1500$ units of catalase; $10 \mu \mathrm{l}$ of $3.9 \mathrm{mM} \mathrm{CuSO} \mathrm{C}_{4}$; and $10 \mu \mathrm{l}$ of $30 \mathrm{mM}$ tyramine as the substrate. In selected tubes, $40 \mathrm{ng}$ of octopamine dissolved in $10 \mu \mathrm{l}$ of water were used as an internal standard. The reaction mixture was incubated at $37^{\circ} \mathrm{C}$ for $30 \mathrm{~min}$. The DBH reaction was then terminated by placing the reaction tubes in an ice-cold bath and by the addition of $100 \mu \mathrm{l}$ of a mixture containing $70 \mu \mathrm{l}$ of $1 \mathrm{M}$ Tris buffer, pH $8.6 ; 10 \mu \mathrm{l}$ of $13.4 \mathrm{~mm}$ EDTA; $10 \mu \mathrm{l}(0.2 \mu \mathrm{Ci})$ of $\left[{ }^{14} \mathrm{C}\right]$ methyl $S$-adenosylmethionine (specific activity $55 \mathrm{mCi}$ / mmol, New England Nuclear); and $10 \mu \mathrm{l}$ of partially purified phenylethanolamine- $N$-methyltransferase (PNMT). The reaction mixture was then incubated for 30 min at $37^{\circ} \mathrm{C}$. The PNMT reaction was terminated by the addition of $0.5 \mathrm{ml}$ of $0.5 \mathrm{M}$ sodium borate buffer, $\mathrm{pH}$ 10.0. The $\left[{ }^{14} \mathrm{C}\right]$ synephrine formed was extracted into 6 $\mathrm{ml}$ of a $3: 2(\mathrm{v} / \mathrm{v})$ mixture of toluene and isoamyl alcohol. Five milliliters of the organic phase were then transferred to scintillation vials containing $2 \mathrm{ml}$ of the toluene/ isoamyl alcohol mixture and dried at $70^{\circ} \mathrm{C}$ under a nitrogen atmosphere. After drying overnight, the residuc was dissolved in $1 \mathrm{ml}$ of ethanol, and the radioactive content was determined after the addition of $10 \mathrm{ml}$ of toluene phosphor.

In preliminary experiments, the amount of $\mathrm{CuSO}_{4}$ used was found to give optimal activity for the cerebral cortical homogenates. Also, linear results were obtained with respect to the amount of tissue protein used and for the time of incubation. Results of the $\mathrm{DBH}$ assay were expressed in nanomoles of octopamine formed per gram wet weight of tissue per hour.

TH assay. TH activity was assayed radioenzymatically by assessing the conversion of $\mathrm{L}-\left[{ }^{3} \mathrm{H}\right]$ tyrosine to $\left[{ }^{3} \mathrm{H}\right]$ DOPA. The procedure is based on the technique previously reported by Coyle and Axelrod (1972) with several modifications, the most significant of which is the use of ascorbic acid and ferrous sulfate as activators of $\mathrm{TH}$ (Lerner et al., 1978). Cortical tissue was homogenized in 4 vol of $0.01 \mathrm{M}$ Tris buffer, $\mathrm{pH} 6.0$, containing $0.2 \%$ Triton X-100. All procedures were performed at 0 to $4^{\circ} \mathrm{C}$ unless stated otherwise. The homogenate was centrifuged at $25,000 \times g$ for $30 \mathrm{~min}$. Fifty microliters of the supernatant were used for the assay (i.e., $10 \mathrm{mg}$ of cortex). The final volume of the assay mixture was $100 \mu \mathrm{l}$, which, in addition to tissue supernatant, contained potassium phosphate buffer, $0.05 \mathrm{M}, \mathrm{pH} 5.5$; ascorbic acid, $0.02 \mathrm{M}$; ferrous sulfate, $0.1 \mathrm{mM} ; 1 \mathrm{mg}$ of catalase (2000 units); DL-6-methyl-5,6,7,8-tetrahydropterine, $1.6 \mathrm{mM}$; nonradioactive L-tyrosine, $0.2 \mathrm{mM}$; and $1 \mu \mathrm{Ci}$ of side chain $(2,3)$-labeled $\mathrm{L}-\left[{ }^{3} \mathrm{H}\right]$ tyrosine (specific activity $15 \mathrm{Ci} /$ mmol, Amersham). Radioactive tyrosine was purified immediately prior to use by mixing with $4 \mathrm{vol}$ of $0.005 \mathrm{M}$ Tris buffer, $\mathrm{pH} 8.6$, and agitated three times with activated alumina. Blanks consisted of homogenization buffer instead of tissue homogenate supernatant. The reaction mixture was incubated for $30 \mathrm{~min}$ at $37^{\circ} \mathrm{C}$, and the reaction was terminated by the additon of $6 \mathrm{ml}$ of ice-cold $0.4 \mathrm{M}$ perchloric acid containing $6 \mu \mathrm{g}$ of $\mathrm{L}$-DOPA. Two hundred milligrams of alumina, $30 \mathrm{mg}$ of sodium bisulfate, $5 \mathrm{ml}$ of $2 \%$ EDTA, and $1.5 \mathrm{ml}$ of $0.35 \mathrm{M}$ potassium biphosphate were added, and the mixture was stirred and titrated to a $\mathrm{pH}$ of 8.6 with $1 \mathrm{M} \mathrm{NaOH}$. They were then poured over columns that were previously packed with $200 \mathrm{mg}$ of activated alumina and were washed with $20 \mathrm{ml}$ of water. The $\left[{ }^{3} \mathrm{H}\right] D O P A$ formed was eluted with $2.5 \mathrm{ml}$ of $0.2 \mathrm{M}$ acetic acid and counted in 15 $\mathrm{ml}$ of ACS II (Amersham) in a Packard Tricarb 300 liquid scintillation counter at an efficiency of about $42 \%$. Recovery of $\mathrm{L}-\left[{ }^{14} \mathrm{C}\right] \mathrm{DOPA}$ from the alumina columns when it was added to the reaction mixture was about $56 \%$.

In preliminary experiments, we have determined the assay to be linear with respect to time for up to $40 \mathrm{~min}$ and with respect to the amounts of tissue used. Activity of TH was calculated in nanomoles of $\left[{ }^{3} \mathrm{H}\right] D O P A$ formed per gram wet weight of tissue per hour.

$N E$ assay. Samples of the cerebral cortex was weighed in the frozen condition and homogenized in $0.1 \mathrm{M}$ perchloric acid, and the homogenates were centrifuged at $15,000 \times g$ for $10 \mathrm{~min}$ at 0 to $4^{\circ} \mathrm{C}$. The supernatant was assayed for its content of $\mathrm{NE}$ by the radioenzymatic procedure of Henry et al. (1975). We continued to assay NE by this procedure because high performance liquid chromatography with electrochemical detection (HPLCEC) was not available to us at the beginning of this study.

Assay for DA, DOPAC, HVA, 5-HT, and 5-HIAA. The amines and their metabolites were determined by HPLCEC according to the procedure of Wagner et al. (1982) with minor modifications. Cortical samples were weighed in the frozen condition and homogenized in $10 \mathrm{vol}$ of 0.1 $M$ perchloric acid, and 50 to $100 \mu \mathrm{l}$ of the supernatant were directly injected into the system. The HPLC-EC system used was model LC-304 CA (Bioanalytical Systems) with a biophase (ODS $5 \mu \mathrm{m}$ ) column measuring 25 $\mathrm{cm}$ in length and $4 \mathrm{~mm}$ in diameter. The potential at the glassy-carbon electrode was maintained at $+0.85 \mathrm{~V}$ against a silver-silver chloride reference electrode. The mobile phase consisted of an 89:11 (vol/vol) mixture of $0.2 \mathrm{M} \mathrm{NaH}_{2} \mathrm{PO}_{4}$ and methanol with $2.5 \mathrm{mM}$ heptane sulfonic acid, $1 \mathrm{mM}$ EDTA, and $0.5 \mathrm{~mm}$ triethylamine, and the PH was adjusted to 2.70 with phosphoric acid. The flow rate was kept at $1.7 \mathrm{ml} / \mathrm{min}$. This procedure yielded complete separation of the aimes and their metabolites.

Data analysis. Biochemical results from the cerebral cortex ipsilateral to LC lesion were compared to those from the contralateral cortex by the paired $t$ test (twotailed). Results from the contralateral cortex were compared to those from nonlesioned controls by the nonpaired $t$ test (two-tailed).

\section{Results}

The site of 6-OHDA infusion could only barely be discerned in tissue sections stained with hematoxylin and eosin (Fig. 1, $A$ and $B$ ). The fine tract created by the glass micropipette was a major clue for the localization of the lesion site. In tissue sections stained with cresyl violet and viewed under higher magnification, the effect of 6-OHDA infusion into the region of the LC can be more easily ascertained by the paucity of neurons and the presence of reactive cells (Fig. $1 C$ ). In sharp contradistinction, tissue sections prepared for monoamine his- 

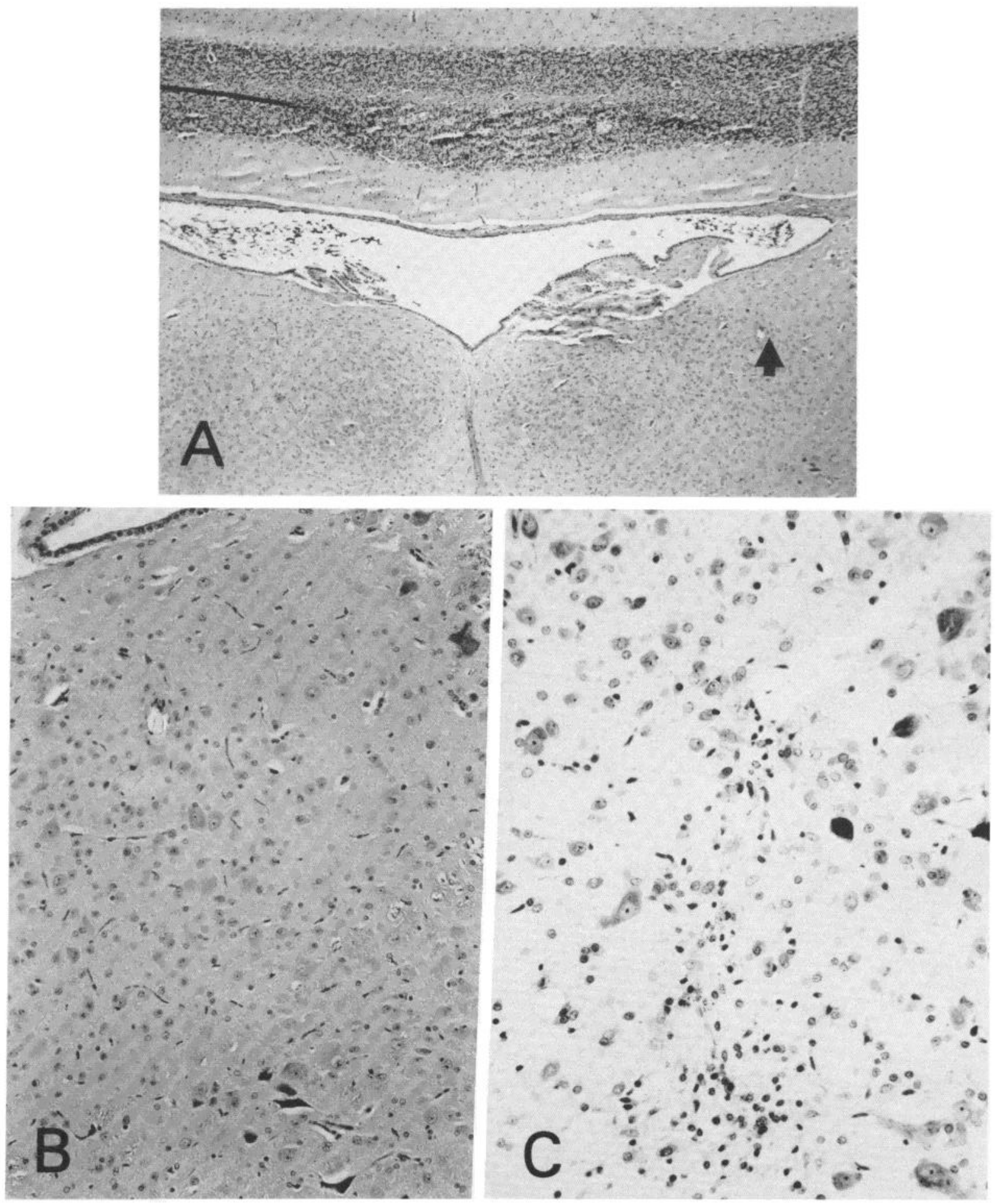

Figure 1. Sections of the pons showing the site of 6-OHDA injection 2 weeks earlier. The NE content of the frontal cerebral cortex ipsilateral and contralateral to the injection was 39 and $246 \mathrm{ng} / \mathrm{gm}$, respectively. In $A$, the arrow indicates the site of injection. The micropipette tract through the cerebellum could be seen above the injection site. Hematoxylin and eosin, magnification $\times 50 . B$ shows the injection site under higher magnification $(\times 130)$. The large neurons of the mesencephalic nucleus of the trigeminal nerve are visible in the right upper corner. Little evidence of tissue destruction or reaction could be seen in hematoxylin and eosin-stained sections. $C$ shows higher magnification $(\times 200)$ of the lesion site taken from an adjacent section and stained with cresyl violet. Note the relative paucity of neurons and the presence of reactive microglia at the injection site.

tofluorescence showed an almost complete loss of the fluorescent neurons of the LC on the lesioned side (Fig. $2 A$ ), while the contralateral LC showed a normal complement of histofluorescent neurons (Fig. $2 B$ ). As ex- pected, this loss of the vast majority of fluorescent LC neurons on the lesioned side was accompanied by a severe decrease in the number of fluorescent fibers and vericosities in the ipsilateral cerebral cortex (Fig. 3). The results 

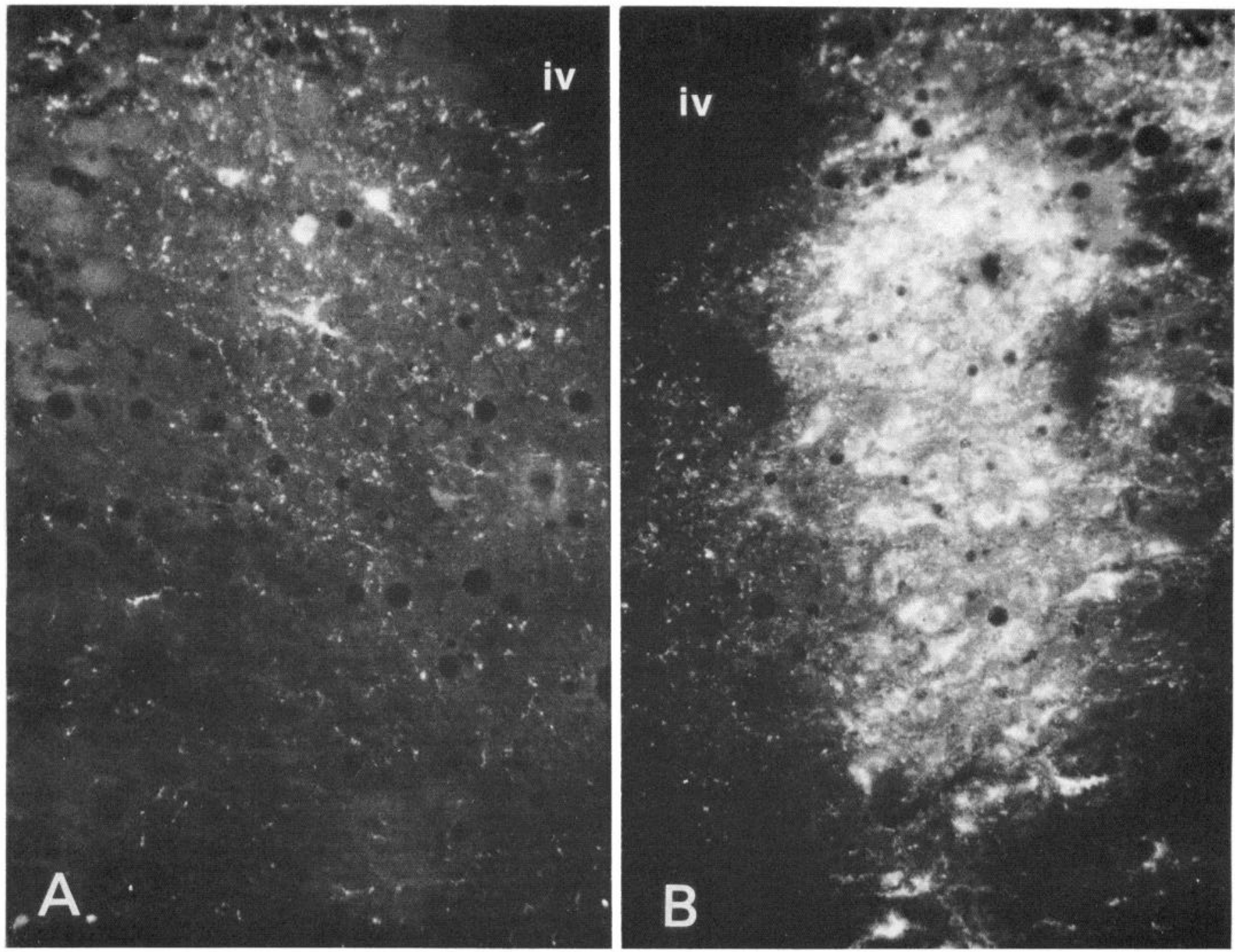

Figure 2. Catecholamine histofluorescence in a section of the pons at the level of the LC 2 weeks after unilateral microinfusion of $5 \mu \mathrm{g}$ of 6-OHDA. $A$ (left) shows few histofluorescent cell bodies remaining in the LC ipsilateral to the infusion site. The neurons of the subceruleus are also affected. In contrast, the contralateral LC (B, right) shows a normal complement of fluorescent neurons. The subceruleus is partially seen at the bottom. The IV ventricle could be seen in the upper right and left corners of $A$ and $B$. Magnification $\times 161$.

of the microscopic studies provide strong evidence that 6-OHDA infusion into the region of the LC produce severe destruction of the noradrenergic neurons of the LC without appreciable nonspecific tissue changes or necrosis.

The acute and long-term effects of unilateral LC lesion and sham operation on cortical NE levels and DBH enzyme activity are shown in Table I. Two weeks after unilateral LC lesion, DBH activity in the ipsilateral cerebral cortex declined by $87 \%$ and was associated with $86 \%$ depletion of cortical NE levels. Eight weeks after the lesion, DBH activity was still reduced by $79 \%$ with a similar decrease in NE levels. Also, there were no significant differences in DBH activity or NE levels between results obtained from the cerebral cortex of unlesioned controls and those of the contralateral cerebral cortex of rats with unilateral LC lesion, both at 2 and 8 weeks after lesion. The large decreases in NE levels and DBH activity that are produced by unilateral LC lesion and the restriction of this effect to the ipsilateral cerebral cortex are consistent with previous reports from our laboratory (Harik et al., 1981).

The short- and long-term effects of unilateral LC lesion on the activity of TH and levels of NE in the cerebral cortex ipsilateral and contralateral to the LC lesion and in sham-operated controls are shown in Table II. The results are very similar to those described above for $\mathrm{DBH}$. TH activity was decreased by $81 \%$ in the ipsilateral cerebral cortex 2 weeks after the lesion with a comparable decrease in tissue NE. Eight weeks after LC lesion, TH activity remained low in the ipsilateral cerebral cortex, and there was no evidence to suggest recovery. Tissue NE levels also remained markedly depleted. It is interesting to note that $\mathrm{TH}$ activity was increased in the cerebral cortex contralateral to LC lesion in comparison to the unlesioned controls $(p<0.05)$ at 2 weeks after lesion (Table II).

The effects of unilateral LC lesion or cerebral monoamines and their metabolites are detailed in Table III. $\mathrm{NE}$ levels were again noted to be depleted by about $90 \%$ 


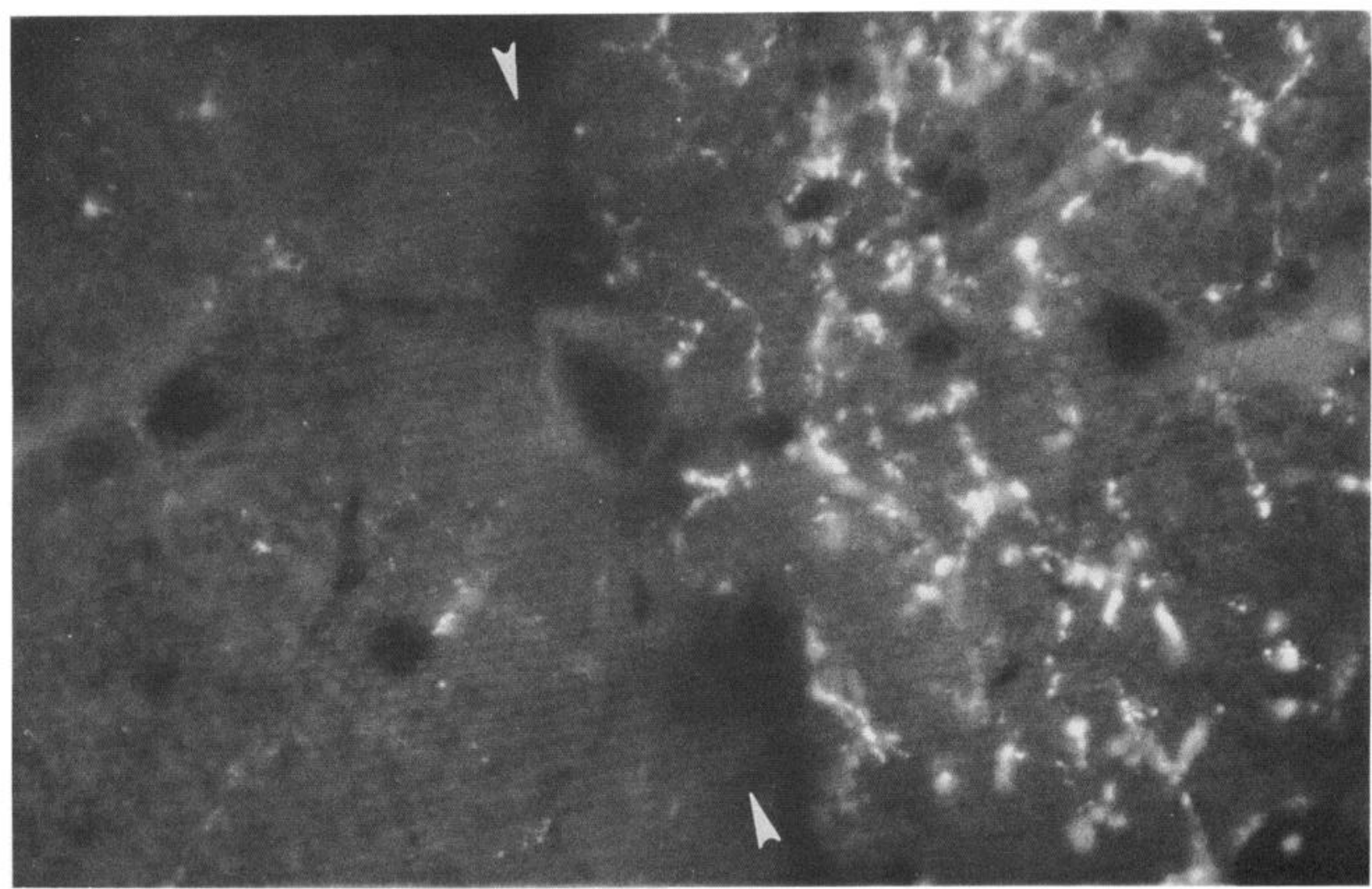

Figure 3. Catecholamine histofluorescence in fibers and varicosities in the cingulate gyri of the same rat brain shown in Figure 2. The arrow shows the interhemispheric fissure. Note the contrast between histofluorescence in the cortex ipsilateral to the LC lesion (to the left) and the contralateral cingulate cortex (to the right). Magnification $\times 980$. The NE content of the frontal cerebral cortex ipsilateral and contralateral to the LC lesion was 43 and $361 \mathrm{ng} / \mathrm{gm}$, respectively.

TABLE I

Acute and long-term effects of unilateral locus ceruleus (LC) lesion on the activity of dopamine $\beta$-hydroxylase (DBH) and norepinephrine (NE) levels in the cerebral cortex

Rats were killed 2 and 8 weeks after unilateral LC lesion or sham operation. Values denote means \pm SEM. The number of observations is in parentheses.

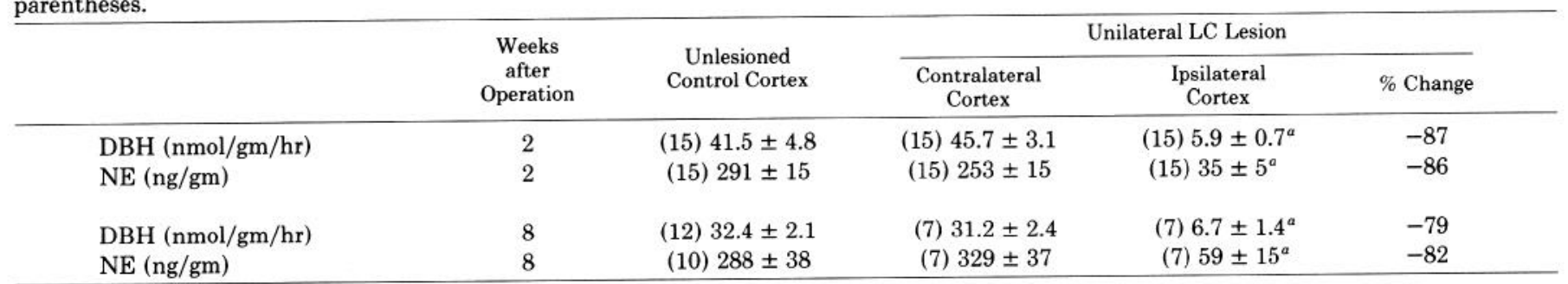

${ }^{a}$ Results of contralateral and ipsilateral cortex different at $p<0.001$ (paired $t$ test, two-tailed).

in the cerebral cortex ipsilateral to LC lesion. DA and its metabolites, DOPAC and HVA, were all increased in the ipsilateral cortex 2 weeks after LC lesion, and this increase remained significant for $\mathrm{HVA}$ at 8 weeks after lesion. 5-HT levels were not altered by LC lesion, although there was some increase in 5-HIAA levels in the ipsilateral cortex at 2 weeks (Table III).

\section{Discussion}

We have previously proposed that the unilateral selective chemical lesion of the LC by the local microinjection of 6-OHDA results in marked depletion of $\mathrm{NE}$ in the ipsilateral cerebral cortex while leaving the contralateral cerebral cortex as an internal control (Harik et al., 1979, 1981, 1982; LaManna et al., 1981; Sharma et al., 1981). However, we found that despite the continued and severe depletion of cortical NE ipsilateral to LC lesion, many of the abnormalities that were noted 2 weeks after the lesion returned to normal within 4 to 8 weeks (Harik et al., 1981). The mechanism(s) underlying the compensatory changes that become operative after chronic LC lesion is not known. In this study, we sought to investigate possible biochemical changes that may correlate with the recovery of functions after LC lesion. Such correlation does not necessarily imply a cause and effect relationship but may help in understanding the nature 
TABLE II

Acute and long-term effects of unilateral locus ceruleus (LC) lesion on the activity of tyrosine hydroxylase (TH) and norepinephrine (NE) levels in the cerebral cortex

Rats were killed 2 and 8 weeks after unilateral LC lesion or sham operation. Values denote means \pm SEM. The number of observations is in parentheses.

\begin{tabular}{|c|c|c|c|c|c|}
\hline & \multirow{2}{*}{$\begin{array}{c}\text { Weeks } \\
\text { after } \\
\text { Operation }\end{array}$} & \multirow{2}{*}{$\begin{array}{l}\text { Unlesioned } \\
\text { Control Cortex }\end{array}$} & \multicolumn{3}{|c|}{ Unilateral LC Lesion } \\
\hline & & & $\begin{array}{l}\text { Contralateral } \\
\text { Cortex }\end{array}$ & $\begin{array}{l}\text { Ipsilateral } \\
\text { Cortex }\end{array}$ & $\%$ Change \\
\hline $\mathrm{TH}(\mathrm{nmol} / \mathrm{gm} / \mathrm{hr})$ & 2 & (13) $16.1 \pm 0.8^{a}$ & (9) $19.8 \pm 1.5$ & (9) $3.7 \pm 1.1^{b}$ & -81 \\
\hline $\mathrm{TH}(\mathrm{nmol} / \mathrm{gm} / \mathrm{hr})$ & 8 & (5) $11.0 \pm 1.1$ & (9) $16.8 \pm 1.9$ & (7) $2.7 \pm 0.5^{b}$ & -84 \\
\hline $\mathrm{NE}$ (ng/gm) & 8 & (6) $270 \pm 15$ & (9) $271 \pm 31$ & (9) $21 \pm 4^{b}$ & -92 \\
\hline
\end{tabular}

${ }^{a}$ Results of control rats different from those of contralateral cortex at $p<0.05$ (nonpaired $t$ test, two-tailed).

${ }^{b}$ Results of contralateral and ipsilateral cortex different at $p<0.001$ (paired $t$ test, two-tailed).

TABLE III

Acute and long-term effects of unilateral locus ceruleus ( $L C$ ) lesion on the concentration of monoamines and their metabolites in the cerebral cortex ${ }^{a}$

\begin{tabular}{lccccll}
\hline & $\begin{array}{c}\text { Weeks } \\
\text { after } \\
\text { Operation }\end{array}$ & No. & $\begin{array}{c}\text { Contralateral } \\
\text { Cortex }\end{array}$ & $\begin{array}{l}\text { Ipsilateral } \\
\text { Cortex }\end{array}$ & \% Change Significance \\
& 2 & 17 & $260 \pm 20$ & $18 \pm 3$ & -93 & $p<0.001$ \\
NE & 2 & 17 & $27 \pm 6$ & $67 \pm 19$ & +148 & $p=0.058$ \\
DA & 2 & 13 & $5 \pm 1$ & $16 \pm 4$ & +220 & $p<0.01$ \\
DOPAC & 2 & 17 & $20 \pm 5$ & $30 \pm 7$ & +50 & $p<0.001$ \\
HVA & 2 & 17 & $264 \pm 30$ & $289 \pm 37$ & +9 & NS $^{c}$ \\
5-HT & 2 & 17 & 264 & \\
5-HIAA & 2 & 17 & $192 \pm 11$ & $221 \pm 6$ & +15 & $p<0.01$ \\
& & & & & & \\
NE & 8 & 8 & $283 \pm 30$ & $27 \pm 8$ & -90 & $p<0.001$ \\
DA & 8 & 8 & $13 \pm 3$ & $27 \pm 15$ & +108 & NS \\
DOPAC & 8 & 8 & $11 \pm 3$ & $16 \pm 4$ & +45 & NS \\
HVA & 8 & 4 & $29 \pm 4$ & $43 \pm 7$ & +48 & $p=0.062$ \\
5-HT & 8 & 8 & $270 \pm 35$ & $282 \pm 32$ & +4 & NS \\
5-HIAA & 8 & 8 & $216 \pm 24$ & $203 \pm 25$ & -6 & NS \\
\hline
\end{tabular}

${ }^{a}$ Values denote means \pm SEM in nanograms per gram wet weight of tissue.

${ }^{b}$ Results of contralateral and ipsilateral cortex were compared by the paired $t$ test, two-tailed.

${ }^{c} \mathrm{NS}$, not significant.

of the compensatory processes after LC lesion and may shed light on the general question of regeneration and recovery of function after injury to the central nervous system.

Several possibilities that may explain the recovery of function after LC lesion include: (i) Regeneration of noradrenergic LC neurons after their reversible injury by 6 -OHDA. Previous work has documented regeneration of noradrenergic terminals after intracisternal $(\mathrm{Ny}-$ gren and Olson, 1976) and intraspinal (Nygren et al., 1971) injections of 6-OHDA. Since noradrenergic neuronal cell bodies are known to be less sensitive to 6OHDA than axons and terminals, it is possible that their injury by $6-\mathrm{OHDA}$ perfusion could be transient. (ii) Another possibility involves an increase in the activity of $\mathrm{TH}$, the rate-limiting enzyme in catecholamine biosynthesis. Acheson et al. (1980) reported marked increase in $\mathrm{TH}$ activity in rat brain after intraventricular injection of 6-OHDA. Such increased enzyme activity involves an early activation detectable only in the presence of suboptimal $\mathrm{pH}$ conditions and low cofactor concentrations, and a later increase in the apparent $V_{\max }$ of the enzyme
(Acheson and Zigmond, 1981). They estimate a 3- to 4fold increase in the amount of TH per residual noradrenergic terminal to explain the increased ratio of $\mathrm{TH}$ activity to NE levels after intraventricular 6-OHDA. (iii) A third possible explanation for the observed recovery of function is the proliferation of other noradrenergic terminals emanating from neurons outside the LC or of dopaminergic terminals that are ordinarily present in very small numbers in the parietal cortex, to replace the degenerating terminals of LC neurons. Recent evidence of such proliferation of dopaminergic endings in the parietal cerebral cortex ipsilateral to LC lesion has been presented by Logan and Harik (1982).

The results presented in this communication do not support the first two possibilities mentioned above. Although it is conceivable that recovery of function of the ceruleocortical connections can occur despite continued depletion of tissue NE levels if the turnover of the active pool of NE is increased, such as explanation would necessitate some recovery of activity of the synthesizing enzymes, TH and DBH. The lack of such recovery, in addition to the long-term marked decrease in the high affinity uptake for NE in the ipsilateral cerebral cortex after LC lesion (Logan and Harik, 1982), renders the possibility of regeneration or hyperactivity of the remaining ceruleocortical connections unlikely. It should be kept in mind, however, that our assays for $\mathrm{TH}$ and DBH activities were done in vitro under saturating conditions of substrates and cofactors and under optimal requirements. It is possible that in vivo conditions may be less than optimal and that the activities of these enzymes in vivo may be more efficient in the NE-depleted cortex.

The levels of DA, DOPAC, and HVA were all increased in the ipsilateral cerebral cortex at 2 weeks after LC lesion. The levels of DA and DOPAC were somewhat higher in the NE-depleted cortex at 8 weeks after LC lesion, but these increases did not reach statistical significance. HVA levels in the ipsilateral cortex remained higher at 8 weeks after LC lesion $(p=0.062)$. The results are very suggestive of, but do not definitely prove, the hypothesized increased dopaminergic activity in the cerebral cortex ipsilateral to LC lesion. The finding by Worth et al. (1976) of a 2 -fold increase in the levels of DA in the ipsilateral "posterior cerebrum" 12 weeks after unilateral electrolytic lesion of the LC supports the results presented in this manuscript and the hypothesis 
that dopaminergic terminals proliferate to replace the degenerated noradrenergic terminals. However, it may be possible to explain the increased levels of DA and its metabolites on hyperactivity of remaining LC neurons that may have escaped injury during the lesion process if we assume increased in vivo activity of $\mathrm{TH}$ (which we did not detect in our in vitro assay) without an accompanying increase in the activity of DBH. This assumption will render DBH the rate-limiting step in NE synthesis and may cause accumulation of DA and increased levels of its metabolites.

In addition to the query regarding the biochemical correlates of the recovery of function after chronic LC lesion, the results of this study address two other important questions. The first pertains to the specificity and selectivity of the LC lesion by the stereotaxic microinfusion of 6-OHDA, and the second relates to the effect of such LC lesion on the contralateral cerebral cortex.

The magnitude of depletion of $\mathrm{NE}$ and its synthesizing enzymes induced by 6-OHDA lesions is larger than that obtained after electrolytic lesions of the LC (Korf et al., 1973; Kobayashi et al., 1975; Worth et al., 1976) or the ascending noradrenergic pathways at the level of the hypothalamus (Reis and Ross, 1973). Despite the marked loss of noradrenergic presynaptic markers, 6-OHDA lesion of the LC does not cause loss of any other putative neurotransmitter marker (Logan and Harik, 1982). The structural results presented here support our contention, previously based on biochemical evidence, that such lesion of the LC results in near complete destruction of noradrenergic neurons without gross evidence of nonspecific tissue destruction. Also, our results show no loss of DA or 5-HT and their metabolites in the ipsilateral cerebral cortex. The nonspecific depletion of monoamines is a frequent complication of medial forebrain bundle lesions (Moore and Heller, 1967) and intracisternal or intraventricular 6-OHDA infusions.

We have not been able to cause total depletion of cortical NE after unilateral LC lesion by 6-OHDA. It is unlikely that this is due to innervation contributed by the contralateral LC, since bilateral 6-OHDA-induced LC lesions did not increase the magnitude of cortical NE loss (S. I. Harik, unpublished observations). We suspect that about $10 \%$ of the NE content of the cerebral cortex may be localized in synaptic terminals of neurons whose cell bodies are located outside of the central nervous system.

The effects of unilateral LC lesion on the contralateral cerebral cortex and the mechanisms that underlie such effects have been the subject of controversy (Reis and Ross, 1973; Kobayashi et al., 1975). Electrolytic lesions of the LC and the ascending noradrenergic pathways have caused an increase in NE levels (Worth et al., 1976) and DBH activity (Reis and Ross, 1973) in the contralateral cortex between 2 and 12 weeks after lesion. Results presented in this communication, as well as previous work from our laboratory (Harik et al., 1981; LaManna et al., 1981; Sharma et al., 1981), fail to confirm a consistent increase in $\mathrm{NE}$ levels or $\mathrm{DBH}$ activity in the contralateral cerebral cortex. However, the activity of $\mathrm{TH}$ was significantly increased in the contralateral cerebral cortex 2 weeks after LC lesion $(p<0.05$, Table
II). The cause of this effect remains unknown, but an inhibitory synaptic effect of one LC on its contralateral counterpart is suspected (Sakai et al., 1977).

In conclusion, we believe that unilateral LC lesion by the local microinfusion of 6-OHDA is a simple, specific, and reproducible method that causes marked depletion of $\mathrm{NE}$ and loss of activity of its synthesizing enzymes, $\mathrm{TH}$ and $\mathrm{DBH}$, in the ipsilateral cerebral cortex. These changes were not reversible during the 8-week period of the study. Increased levels of DA and its metabolites in the ipsilateral cortex are considered as supportive but not conclusive evidence for the hypothesis that overactivity of dopaminergic mechanisms may underlie the functional long-term recovery noted after LC lesion.

\section{References}

Acheson, A. L., and M. J. Zigmond (1981) Short and long term changes in tyrosine hydroxylase activity in rat brain after subtotal destruction of central noradrenergic neurons. J. Neurosci. 1: 493-504.

Acheson, A. L., M. J. Zigmond, and E. M. Stricker (1980) Compensatory increase in tyrosine hydroxylase activity in rat brain after intraventricular injections of 6-hydroxydopamine. Science 207: 537-540.

Amaral, D. G., and H. M. Sinnamon (1977) The locus coeruleus: Neurobiology of a central noradrenergic nucleus. Prog. Neurobiol. 9: 147-196.

Coyle, J. T., and J. Axelord (1972) Tyrosine hydroxylase in rat brain: Developmental characteristics. J. Neurochem. 19: 1117-1123.

de la Torre, J. C. (1980) An improved approach to histofluorescence using the SPG method for tissue monoamines. J. Neurosci. Methods 3: 1-5.

Harik, S. I., J. C. LaManna, A. I. Light, and M. Rosenthal (1979) Cerebral norepinephrine: Influence on cortical oxidative metabolism in situ. Science 206: 69-71.

Harik, S. I., R. B. Duckrow, J. C. LaManna, M. Rosenthal, V. K. Sharma, and S. P. Banerjee (1981) Cerebral compensation for chronic noradrenergic denervation induced by locus ceruleus lesion: Recovery of receptor binding, isoproterenolinduced adenylate cyclase activity and oxidative metabolism. J Neurosci. 1: 641-649.

Harik, S. I., R. Busto, and E. Martinez (1982) Norepinephrine regulation of cerebral glycogen utilization during seizures and ischemia. J. Neurosci. 2: 409-414.

Henry, D. P., B. J. Starman, D. G. Johnson, and R. H. Williams (1975) A sensitive radioenzymatic assay for norepinephrine in tissue and plasma. Life Sci. 16: 375-384.

Kobayashi, R. M., M. Palkovits, D. M. Jacobowitz, and I. J. Kopin (1975) Biochemical mapping of the noradrenergic projection from the locus coeruleus. Neurology 25: 223-233.

Korf, J., G. K. Aghajanian, and R. H. Roth (1973) Stimulation and destruction of the locus coeruleus: Opposite effects on 3methoxy-4-hydroxyphenylglycol sulfate levels in the rat cerebral cortex. Eur. J. Pharmacol. 21: 305-310.

LaManna, J. C., S. I. Harik, A. I. Light, and M. Rosenthal (1981) Norepinephrine depletion alters cerebral oxidative metabolism in the "active" state. Brain Res. 204: 87-101.

Lerner, P., P. Nosé, M. M. Ames, and W. Lovenberg (1978) Modification of the tyrosine hydroxylase assay. Increased enzyme activity in the presence of ascorbic acid. Neurochem. Res. 3: 641-651.

Levitt, M., S. Spector, A. Sjoerdsma, and S. Udenfriend (1965) Elucidation of the rate-limiting step in norepinephrine biosynthesis in the perfused guinea-pig heart. J. Pharmacol. Exp. Ther. 148: 1-8. 
Logan, W. J., and S. I. Harik (1982) Specific uptake of norepinephrine and dopamine by homogenates of rat cerebral cortex after locus ceruleus lesion. J. Neurosci. 2: 394-398.

Molinoff, P. B., R. Weinshilboum, and J. Axelrod (1971) A sensitive enzymatic assay for dopamine B hydroxylase. J. Pharmacol. Exp. Ther. 178: 425-431.

Moore, R. Y., and A. Heller (1967) Monoamine levels and neuronal degeration in rat brain following lateral hypothalmic lesions. J. Pharmacol. Exp. Ther. 156: 12-22.

Nygren, L. -G., and Olson, L. (1976) On spinal noradrenaline receptor supersensitivity correlation between nerve terminal densities and flexor reflexes at various times after intracisternal 6-hydroxydopamine. Brain Res. 116: 455-470.

Nygren, L. -G., L. Olson, and A. Seiger (1971) Regeneration of monoamine-containing axons in the developing and adult spinal cord of the rat following intraspinal 6-OH-dopamine injections or transections. Histochemie 28: 1-15.

Reis, D. J., and R. A. Ross (1973) Dynamic changes in brain dopamine- $\beta$-hydroxylase activity during anterograde and retrograde reactions to injury of central noradrenergic axons.
Brain Res. 57: 307-326.

Sakai, K., D. Touret, D. Salvert, L. Leger, and M. Jouvet (1977) Afferent projections to the cat locus coeruleus as studied by the horseradish peroxidase technique. Brain Res. 119: 21-41.

Sharma, V. K., S. I. Harik, R. Busto, and S. P. Banerjee (1981) Effects of noradrenaline depletion on adrenergic and muscarinic cholinergic receptors in the cerebral cortex, hippocampus and cerebellum. Exp. Neurol. 72: 179-194.

Wagner, J., P. Vitali, M. G. Palfreyman, M. Zraika, and S. Huot (1982) Simultaneous determination of 2,4-dihydroxyphenylalanine, 5-hydroxytryptophan, dopamine, 4-hydroxy3-methoxyphenylalanine, norepinephrine, 3,4-dihydroxyphenylacetic acid, homovanillic acid, serotonin, and 5-hydroxyindoleacetic acid in rat cerebrospinal fluid and brain by high-performance liquid chromatography with electrochemical detection. J. Neurochem. 38: 1241-1254.

Worth, W. S., J. Collins, D. Kett, and J. H. Austin (1976) Serial changes in norepinephrine and dopamine levels after locus ceruleus lesions. Brain Res., 106: 198-203. 